\title{
Virtual Reality: A Simple Substitute or New Niche?
}

\author{
Victoria-Ann Verkerk $^{\left({ }^{(}\right)}$(D) \\ University of Pretoria, Pretoria 002, South Africa
}

\begin{abstract}
Since 2020, the tourism industry worldwide has been devastated as a result of the COVID-19 pandemic. Governments across the globe imposed strict national lockdowns in order to curb the spread of the pandemic, with negative effects on tourism. This forced many tourism companies and organizations to turn to virtual reality (VR) to survive. As a consequence, numerous tourism scholars began to question whether VR would replace conventional tourism after COVID-19. The study aims is to address this concern and to determine if VR will be a substitute for conventional tourism or whether it can be considered as a tourism niche. It is a conceptional study which adopts a comparative analysis of conventional tourism models and VR. It uses two popular conventional tourism models, namely N. Leiper's (1979) tourism system model and R. W. Butler's (1980) destination life-cycle model. Based on this analysis, this paper suggests that VR will never be a substitute for conventional tourism, but should rather be considered a future tourism niche.
\end{abstract}

Keywords: Virtual Reality $\cdot$ Conventional tourism $\cdot$ Tourism models

\section{Introduction}

Tourism has faced several crises in the past $[9,14]$, however, none of these have had such an impact on tourism as the novel coronavirus disease of 2019 (COVID-19) [14]. To try to minimize the spread of the virus, the majority of governments have implemented non-pharmaceutical measures, such as quarantine, lockdowns, physical distancing, canceling events, and closing land borders to tourists [2, 9, 14]. This caused the tourism industry to come to a literal halt [14]. The United Nations World Tourism Organization estimated that by the end of 2020, international tourist arrivals declined between $70 \%$ to $75 \%$, and as a result, tourism revenue dropped by US\$711.94 billion to US\$568.6 billion, which represented a loss of $20 \%[20,28]$.

It is difficult to predict when, and if, tourism will ever really recover from COVID19. It is estimated by some that it will take the tourism industry up to 10 months to recover after the pandemic [8]. Therefore, it is argued that international tourism will only return between 2021 and 2022 [28]. But the recovery of tourism could take even longer. For example, it took tourism 4.5 years to recover after the $9 / 11$ terrorist attack 
[26]. Thus, tourism scholars argue that technology will play a critical role in building resilience in tourism. One such technology is virtual reality (VR) [1, 14].

In light of this, tourism scholars have begun debating whether VR will act as a substitute for conventional tourism once the COVID-19 pandemic is under control or is over. This study, however, considers whether VR can be regarded as a substitute for conventional tourism or a tourism niche. This will be determined by comparing the most renowned conventional tourism models with VR, namely: N. Leiper's tourism system model (1979) and R.W. Butler's destination life-cycle (TALC) model (1980).

\title{
2 Virtual Reality in Tourism
}

The tourism industry has used VR since the 1990s [4, 15]. Despite this, there is no precise definition of VR in tourism literature [3]. Scholars often rely on and cite the well-known definition of D.A. Guttentag [15]:

\begin{abstract}
the use of a computer-generated environment [the virtual environment] that one can navigate [the ability to move and explore the virtual environment] and possibly interact [to the ability to select and move objects within the virtual environment] with resulting in real time simulation of one or more of the user's five senses.
\end{abstract}

According to Guttentag, there are six main areas where VR provides benefits in tourism, namely: marketing; planning; sustainability and preservation; accessibility; education; and entertainment [15]. For many tourism scholars, VR is also seen as a benefit to tourism, however, they generally tend to focus on two of these areas, namely marketing and sustainability. In terms of marketing, tourism companies and organizations perceive VR as a superior marketing tool. In fact, VR has been described as having revolutionized the way tourism products, services, and experiences are promoted and sold [21, 29]. For example, Tussyadiah et al. [27] state that VR offers potential tourists a "try before buy" experience, which enables them to experience a destination virtually beforehand [7]. This is beneficial as it might encourage potential tourists to physically travel to the actual destination [15].

Tourism scholars and practitioners also regard VR as an ideal sustainable tool. As tourists and tourism-related activities have led to over-tourism, many tourism destinations/sites, especially those that are fragile and sensitive, have been restricted to tourists. However, VR enables tourists to gain "access" to these destinations/sites, without causing physical harm or degradation to the actual destination/site. According to tourism scholars, the reason is that VR provides tourists a substitute, or alternative, version of the real destination/site [7, 15, 29].

On the other hand, for many tourism scholars, VR poses a threat to tourism. According to this view, the major drawback of VR is that it is an individual activity that does not allow tourists any physical interaction with the local community or other tourists. This is a major concern as interaction plays an integral part in the tourist experience as people are social beings that want to be in the company of others [7, 24]. Even though VR can motivate potential tourists to visit the physical destination, it could replace the need to travel - having COVID-19 enhance this. VR might even offer potential tourists a better tourist experience than the real one. This means that potential 
tourists no longer have the desire to travel to the actual destination. For many countries that are dependent on tourism revenue, specifically those in the global South, this is detrimental as it may lead to them suffering economically [7, 23].

Despite these benefits and drawbacks which permeate the scholarship, there is a major gap in the literature as tourism scholars have not yet paid adequate attention to VR as a tourism niche in its own right, but rather as a substitute for conventional tourism. The purpose of this study is, thus, to address the gap, as well as determine whether VR can be regarded as a substitute for conventional tourism or as a tourism niche.

\section{Literature Review}

As indicated, the literature on tourism and VR is relatively limited, with only certain aspects having received any attention. It is apparent that the literature on tourism and VR has essentially focused on select key aspects: marketing, sustainability, VR as a substitute for conventional tourism, and COVID-19. Marketing has been a popular area in VR literature during the last three decades [17]. This is indicated by the wide range of topics, which include some of the following: VR compared with traditional marketing media (e.g., travel brochures) [21], presence [27], and Second Life [18].

Tourism scholars have also discussed how VR can be used as the ultimate tool for sustainability. One of the most-cited authors in this regard is J.M. Dewailly who focuses on how VR contributes to sustainability in tourism [11].

Another area that has become popular among tourism scholars is VR as a substitute for conventional tourism. In his latest publication, Guttentag discusses VR as a substitute for conventional tourism. He concludes that VR will never substitute conventional tourism [16]. In contrast, D. Sarkady et al. disagree by stating that although tourists used VR as a substitute for conventional tourism during COVID-19, they will also do so after the pandemic [25].

Lastly, since 2020, tourism scholars have begun paying attention to how VR can contribute to tourism during COVID-19. O. Atsiz, is one of many scholars that has addressed this topic, focused on how VR can offer tourists an alternative travel experience, while still adhering to physical distancing (or social distancing) regulations [2].

When considering tourism models, it is Butler's TALC model which emerges as one of the most popular conventional tourism models in tourism literature. It has stood the test of time as tourism scholars continue to reference this model and his work as seminal. In addition, the conventional tourism framework model by Leiper is also often favored among tourism scholars.

In terms of VR, the only authors that have paid attention to a conventional tourism model thus far are J. Bulchand-Gidumal and E. William. In their work, they use Leiper's tourism framework model for VR and augmented reality to discuss the main stages of travel - dreaming, planning, booking, transit, experiencing, and sharing. The results of their study show that VR is applicable in the following phases: dreaming (i.e., the "try before buy" concept), planning (i.e., the "try before buy" concept), booking (i.e., the "try before buy" concept), transit (i.e., entertainment), experiencing (i.e., the 
complete tourist experience), and sharing (i.e., social media) [5]. Given the limited attention this topic appears to have received, this study addresses this gap.

\section{Methodology}

As in the case of many tourism studies, this study does not use empirical research such as qualitative and quantitative research methods as it does not rely on experiments. Instead, it adopts a conceptual research approach and a comparative analysis. The conceptual research approach is of relevance as it is often used to address difficult questions and to "develop new concepts ... or [to] reinterpret existing ones" [30]. A multiple comparative methodology was also adopted to more effectively "gauge the significance, validity and reliability of the outcome" [12]. The conventional tourism models devised by Butler and Leiper were selected as benchmarks based on the reason that they have remained popular and reliable since they emerged in the literature. Therefore, they still apply to modern-day tourism research. Another reason is that tourism is constantly changing, thus, the study compares two established conventional tourism models and argues that in doing so the position and status of VR within the tourism realm can be evaluated.

\section{Results and Discussion}

This section focuses on the conventional tourism models by Leiper and Butler and how they can be applied to VR. It is divided into two sections. The first section explains these models in terms of conventional tourism, and the second assesses the similarities and differences between VR and conventional tourism. In other words, it appraises the VR dimension in terms of the two key conventional tourism models.

\subsection{Conventional Tourism Models}

Over the past half-century, as tourism has evolved as a subject of intense academic research, a plethora of tourism-related models have been developed. This section briefly discusses the two conventional tourism models devised by Leiper and Butler that have been selected for this analysis as they have stood the test of time and are still regarded among tourism scholars as key analytical tools. In 1979, Leiper developed the "tourism system" model in order to understand and manage tourism (see Fig. 1). The model comprises of tourists, geographical elements (tourist generating region, the tourist destination region, and the transit and route region), and the tourism industry [19]. 


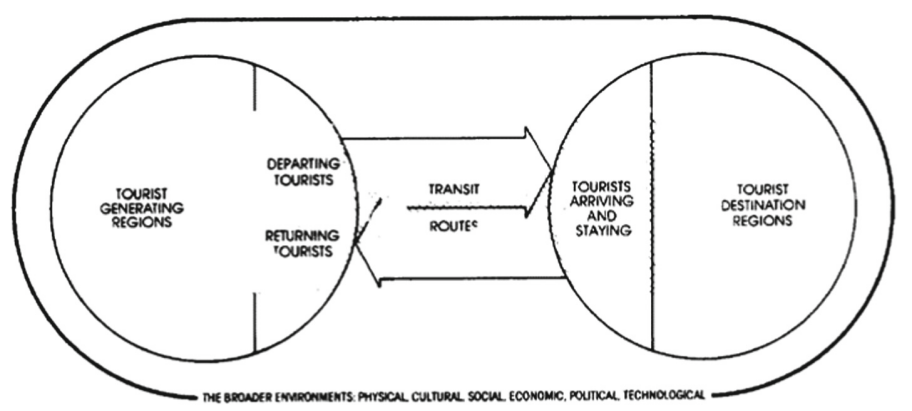

Fig. 1. The tourism system (Source: Leiper, Leiper, N. (1979) The framework of tourism towards a definition of tourism, tourist, and the tourist industry. Annals of Tourism Research 6 (4):404)

According to Leiper's model, the integral component in tourism is the tourists. Fletcher et al. [13] state that tourists "initiate the demand for travel for tourism purposes". Thus, the tourism industry cannot function at all without them [19].

In terms of the geographical elements, they consist of the tourist generating region, the tourist destination region, and the transit and route region. Leiper states that the tourist generating region is "the place where tours begin and end", in other words, tourists' residences [19]. Based on the model, the tourist destination region refers to the area that tourists stay in temporarily, namely the destination [19]. Some scholars are of the opinion that the tourist generating region and the tourist destination region align with G.M.S. Dann's "push" factors (the reason tourists want to travel) and "pull" factors (features of the destination that encourage tourists to travel to the destination) [10]. Based on the model, the tourist generating region "pushes" tourists to travel, while the tourist destination region "pulls" tourists to it [13].

Leiper states that the transit and route region include destinations tourists visit on route. The transit and route region are important factors in tourism as they link the tourist generating region and the tourist destination region with one another [19].

The last element in Leiper's model is the tourism industry. According to him, the tourism industry includes the tourism organizations, companies, and facilities that serve tourists, for example, shops and restaurants [13, 19].

Lastly, as indicated by Leiper, there are five external factors that influence the elements of the model, namely physical, cultural, social, political, and technological [19].

The second model, and one of the most cited in tourism literature, is the "TALC model" (see Fig. 2). In 1980, Butler developed the TALC model in order to showcase the different phases that a conventional destination undergoes. He argues that a conventional destination goes through various phases, including the exploration stage; the involvement stage; the development stage; the consolidation stage; the stagnation stage; the decline stage, and finally the rejuvenation stage [6]. 


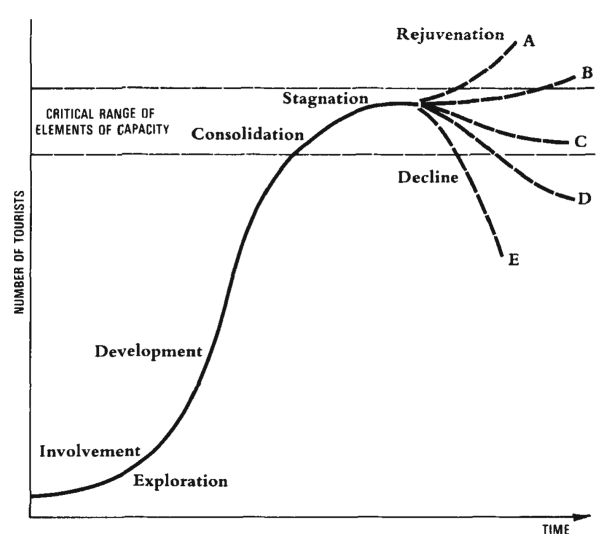

Fig. 2. The tourist destination life-cycle (Source: Butler, R.W. (1980) The concept of a tourist area cycle of evolution: implications for management of resources. Canadian Geographer 24 (1):7)

According to Butler's TALC model, the first phase is the exploration stage. The destination is still unaffected by tourism and is mainly visited by 'early tourists', such as "explorers" (they want to get away from the so-called 'beaten track') and "allocentrics" (adventurous tourists). Since the destination is intact, there is physical interaction between the locals and the visitors. It is for this reason that visitors use local facilities as the infrastructure has not yet been developed for tourism [6].

The TALC model indicates that the second phase is the involvement stage. In the involvement phase, the destination becomes more popular among tourists as it is now being marketed. The locals begin to realize the potential of tourism and start to provide facilities to cater for tourists. It is also during the involvement phase that a tourism season emerges [6].

Butler states that the third phase in the TALC model is the development stage. The destination is still gaining popularity, especially among "mid-centrics" (they visit the destination during its "heydays") and the "institutionalized tourist" (they prefer organized tours). However, the locals' involvement begins to decrease, which opens the door to external tourism organizations. Unfortunately, the external tourism organizations begin to replace the locals and bring in auxiliary facilities, update the existing facilities, and import labor to cater for tourists [6].

The model shows that the next phase in Butler's TALC model is the consolidation stage. The destination is now in its "heyday" as tourists are still increasing and its economy now depends on tourism. But increasingly tourists are no longer interested in the old facilities. Therefore, the external tourism organizations begin to replace the old facilities with newer and improved facilities. This leads to the locals opposing tourism [6].

The fifth phase in Butler's TALC model is the stagnation stage. During this phase, the destination has finally reached its peak in terms of tourist numbers. Tourists still regard the destination as "old fashioned". Only the "organized mass tourist" (who prefers flexible organized tours) and "psychocentric tourist" (who desires a well- 
developed and safe destination) travel to the destination. It is also at the stagnation phase that the natural and cultural attractions deteriorate and, therefore, external tourism organizations replace them with artificial facilities [6].

After the stagnation phase, a destination can either pass through the decline phase or the rejuvenation phase, or both. This depends on how popular the destination is among tourists. Regarding the decline phase, the destination is considered in a tourism slump due to overuse of resources or as a result of war, disease, or any other catastrophic event (as shown by Curves D and E). It is during the decline phase, that the locals begin to show renewed interest in the destination by visiting the destination and purchasing the facilities [6].

In terms of the rejuvenation phase, the destination can be restored to its former glory through successful redevelopment, minor modification, and adjustment to capacity levels, and protection of resources (as shown in Curves A, B, and C) [6].

\subsection{Virtual Reality Tourism Models}

It is argued that Leiper's tourism framework and Butler's TALC model can be used to highlight the similarities between conventional tourism and VR. This section substantiates this viewpoint.

The study argues that Leiper's tourism system is similar to the VR tourism system. The reason is that the VR tourism system also consists of the same core elements, namely tourists, geographical elements, and the tourism industry (see Fig. 3).

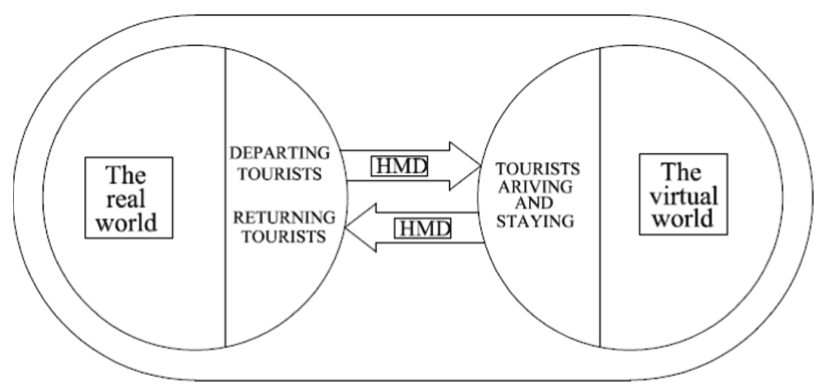

Fig. 3. The tourism system. (Adapted from LeiperN. (1979) The framework of tourism towards a definition of tourism, tourist, and the tourist industry. Annals of Tourism Research 6(4):404)

As indicated by Leiper's model, tourists play a key role in conventional tourism. This is also the case with the VR tourism system. In VR, tourists (i.e., virtual tourists) are important as tourism companies and organizations rely on them to purchase and use their VR-related products and services. Therefore, similar to conventional tourism, it is impossible for VR to function properly without virtual tourists.

In terms of the geographical elements, VR also comprises of three elements similar to those referred to by Leiper. With regards to VR, the real world is considered as the tourist generating region. In the real world, tourists often face challenges and issues on a daily basis, for instance, the COVID-19 pandemic. The tourist destination region 
changes to the virtual world. As highlighted, the tourist generating region and the tourist destination region correspond with Dann's push and pull factors. The reason is that the challenges and issues (e.g., COVID-19) "push" tourists, while the virtual world "pulls" them to it. This is because the virtual world offers tourists a temporary escape from their daily challenges and issues. In order to get to the tourist destination region, tourists "pass through" the transit and route region. In VR, the transit and route region equate to the head-mounted display (HMD). Similar to the conventional tourism model, it is noted that virtual tourists also travel from the tourist generating region (i.e., the real world) pass through the transit and route region through an HMD, and end up at the tourist destination region (i.e., the virtual destination).

Lastly, as regards to Leiper's third aspect, the tourism industry, it is argued that in VR, this comprises of tourism organizations and outlets that order VR-related services and products from VR developer companies to offer tourists the VR tourist experience. It can, therefore, be concluded that Leiper's model shows that VR is in many ways similar to conventional tourism.

The next conventional model is Butler's TALC model. It is argued that a virtual destination also passes through most of the stages referred to by Butler in his TALC model as shown in Fig. 4.

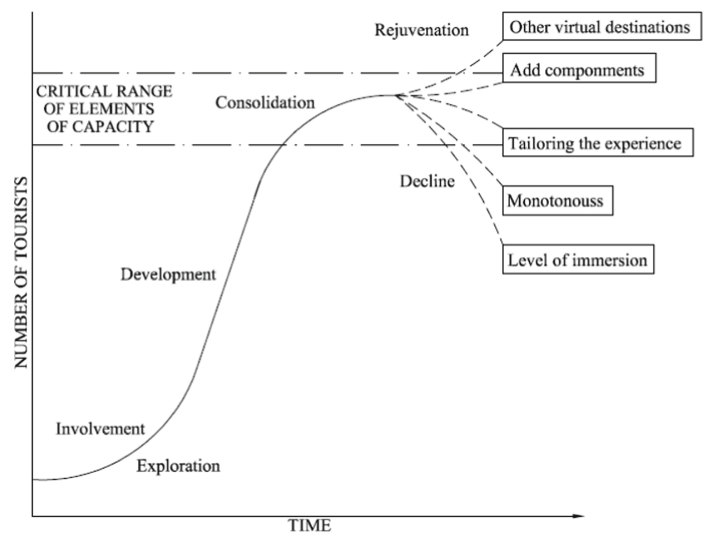

Fig. 4. The tourist destination life-cycle (Adapted from: Butler, R.W. (1980) The concept of a tourist area cycle of evolution: implications for management of resources. Canadian Geographer 24(1):7)

The first phase according to Butler, is the exploration stage. During the exploration phase, not many people are aware of the virtual destination. The only visitor that 'travels' to the destination is the "curious visitor" (who has an eagerness to explore the virtual destination on, for example, the internet due to his/her curiosity). The quality of the virtual destination is poor as tourism organizations provide a very basic or elementary virtual tour since it is cheaper for a start-up. The only downside in the exploration phase, unlike conventional tourism, is that VR does not offer tourists any 
physical interaction between the locals (i.e., VR developer companies) and the curious visitor, as indicated earlier.

The next phase in Butler's TALC model is the involvement stage. Visitor numbers increase as they are becoming more aware of the virtual destination. For this reason, the local VR developer companies begin to show a keen interest in the virtual destination and begin to market it through, for instance, virtual advertisements on the internet. In addition, the local VR developer companies also start to improve the virtual destination by adding other elements, such as higher quality visuals and improved sound.

Following the involvement phase is the development stage. The virtual destination now attracts a new type of tourist, namely the so-called "virtual tourist" (they prefer to explore virtual destinations). It is at the development phase that the virtual destination is in its prime due to its popularity. As a result, there are more virtual tourists compared to the local VR developer companies. In fact, VR has the ability to attract more people than conventional tourism because, for instance, an app of the virtual tour can be downloaded or viewed by many people in comparison to conventional tourism which only allows a certain limited number of tourists according to physical capacity. Unfortunately, the local VR developer companies' involvement can begin to decrease and they are then replaced by international VR developer companies. The international VR developer companies begin to change the virtual environment by upgrading and improving the virtual destination through integrating new components, such as an HMD.

The fourth phase in Butler's TALC model is the consolidation stage. As indicated by the number of downloads or viewers, virtual tourist numbers are still increasing. In addition, the international VR developer companies transform the virtual destination from a basic $360^{\circ}$ video/image virtual tour to a more immersive tour as they add new elements, such as movement (e.g., touch) and sound. The virtual destination begins to rely on the revenue gained from tourism. Hence, the international VR developer companies begin to charge fees for tourists to view the virtual destination. As a result, the local VR companies feel left out and retreat and often go bankrupt.

It is contended that a conventional tourism destination does not always pass through all the phases mentioned in Butler's TALC model. This is also the case with VR. The phase that does not apply to the virtual destination is the stagnation stage. The reason is that a virtual destination will never experience a peak in tourist numbers, cannot be destroyed, and suffer as a result of other issues (i.e., environmental, social, and economic). Moreover, the virtual destination does not have to rely on repeat visitation and lower-income tourists as, unlike a conventional tourism destination, it does not rely on repeat visitation because it is able to attract new and potential tourists regularly.

After the consolidation phase, the virtual destination can pass through the decline phase or the rejuvenation phase, or both. In a sense, the virtual destination does not always experience the decline phase. Again, the reason is that the virtual destination does not exist. Therefore, the virtual destination does not face the same issues as a conventional tourism destination would. However, if the virtual destination does experience the decline phase, it might start to lose tourists due to the tourist experience becoming monotonous and boring, or the level of immersion (as shown by Curves $\mathrm{D}$, and E). In addition, the local VR companies might be involved again in the 
development of the virtual destination. Lastly, the virtual destination will mainly be visited by attitudinal loyal tourists (they show affection towards a certain brand) and behavioral loyal tourists (they continually use or buy the same brand) [22]. In terms of VR, attitudinal loyal tourists are considered poor tourists. They are loyal to the virtual destination since they cannot afford to travel to the actual destination. Behavioral loyal tourists in VR are wealthy tourists that will only visit the virtual destination in order to decide whether it is worth it to visit the actual destination beforehand.

Should the virtual destination experience the decline phase, it can attract tourists again in the rejuvenation phase. VR developers can achieve this by offering tourists another aspect of the virtual destination, make the virtual tour more immersive by adding other components or to tailor the experience according to the need of the tourist (as shown in Curves A, B, C). Therefore, the study argues that the VR destination can be seen to undergo most of the phases that a conventional tourism destination undergoes according to Butler's TALC model.

\section{Conclusion}

As COVID-19 has devastated the tourism industry, many tourism companies and organizations were forced to move to VR in order to survive. VR literally transformed the tourism industry, especially in terms of marketing and sustainability. Therefore, the aim of the study was to determine if VR could become a substitute for conventional tourism or whether it can be considered as a tourism niche, especially in the future. A conceptual and comparative analysis was conducted by comparing two of the most popular conventional tourism models with VR, namely Leiper's tourism system and Butler's TALC model.

Based on the results, VR will not likely be a substitute for conventional tourism. It is, therefore, argued that VR should rather be considered as a tourism niche in its own right. In fact, the conventional tourism model by Leiper supports this. As indicated, VR also consists of similar elements mentioned in Leiper's model, namely tourists, geographical elements, and the tourism industry. Similar to Leiper's conventional tourism system model, in VR, virtual tourists are also regarded as vital as the industry relies on them. In terms of the geographical elements, virtual tourists also have to pass through the tourist generating region (i.e., their reality), the tourist destination region (i.e., the virtual world), and the transit and route region (i.e., HMDs). Lastly, the tourism industry in VR is considered to be the tourism organizations and companies that rely on VR developer companies to develop a VR tourist experience for them to sell to virtual tourists.

Even Butler's TALC model shows that VR is similar to conventional tourism. Based on the model, a virtual destination (i.e., a simple $360^{\circ}$ video/image or live-stream tour of an actual or fabricated destination) also passes through many of the phases, especially the exploration stage; the involvement stage; the development phase; the consolidation phase; the decline phase and the rejuvenation phase. However, the only phase that does not apply to VR is the stagnation stage. Compared to a conventional tourism destination, the virtual destination is virtual, in other words, not "real". Thus, 
the virtual destination will never experience its peak in tourist numbers, destruction, and issues.

Lastly, in order for VR to be considered as a tourism niche in the future, two problems need to be addressed by future scholars. The first major issue is that VR does not entail any physical interaction between the local VR developers and virtual tourists. As indicated, it is important to address the issue because interaction plays a key role in the tourism domain as humans are considered social beings. The second vital issue that has to be focused on is that VR does not provide tourists the full tourist experience as in the case of conventional tourism, where tourists are able to experience a destination through all of the five senses (i.e., sight, sound, smell taste, and touch). This issue needs serious attention because a full sensorial tourist experience will result in a more authentic experience for tourists. For now, VR appears, thus, not to be a substitute for conventional tourism, but rather as a dynamic futuristic niche in its own right.

Acknowledgments. The author would like to thank her supervisor, Prof K.L Harris (Head of Department of the Historical and Heritage Studies and Director of the University of Pretoria Archive) for all her support and guidance during the writing of this paper. The author wishes to thank the University of Pretoria for granting her the necessary funds for her Ph.D. research. Moreover, the author thanks her family and friends for their support. Lastly, the author thanks the ENTER Conference for the opportunity.

\section{References}

1. Akhtar N et al (2021) Post-COVID 19 tourism: will digital tourism replace mass tourism? Sustainability 13:5352-5370. https://doi.org/10.3390/su13105352

2. Atsiz O (2021) Virtual reality technology and physical distancing: a review on limiting human interaction in tourism. J Multidiscip Acad Tour 6:27-35. https://doi.org/10.31822/ jomat. 834448

3. Beck, J. http://www.virtual-reality-in-tourism.com/try-before-you-buy-with-expedia/

4. Beck J, Rainoldi M, Egger R (2019) Virtual reality in tourism: a state-of-the-art review. Tour Rev 74:586-612. https://doi.org/10.1108/TR-03-2017-0049

5. Bulchand-Gidumal J, William E (2020) Tourists and augmented and virtual reality experiences. In: Xiang Z, Gretzel U, Höpken W (eds) Handbook of e-tourism. Springer, Cham, pp 1-20. https://doi.org/10.1007/978-3-030-05324-6_60-1

6. Butler RW (1980) The concept of a tourist area cycle of evolution: implications for management of resources. Can Geogr 24:5-12. https://doi.org/10.1111/j.1541-0064.1980. tb00970.x

7. Cheong R (1995) The virtual threat to travel and tourism. Tour Manag 16:417-422. https:// doi.org/10.1016/0261-5177(95)00049-T

8. Chirisa I et al (2020) Scope for virtual tourism in the times of COVID-19 in select African destinations. J Soc Sci 64:1-13. https://doi.org/10.31901/24566756.2020/64.1-3.2266

9. Gössling S, Scott D, Hall M (2020) Pandemics, tourism and global change: a rapid assessment of COVID-19. J Sustain Tour 29(1):1-20. https://doi.org/10.31901/24566756. 2020/64.13.2266

10. Dann GMS (1981) Tourist motivation an appraisal. Ann Tour Res 8:187-219. https://doi. org/10.1016/0160-7383(81)90082-7 
11. Dewailly JM (1999) Sustainable tourist space: from reality to virtual reality? Tour Geogr 1:41-55. https://doi.org/10.1080/14616689908721293

12. Domínguez-Mujica J (2016) Comparative study. In: Jafari J, Xiao H (eds) Encyclopedia of tourism. Springer, Cham, pp 174-175. https://doi.org/10.1007/978-3-319-01384-8

13. Fletcher J, Fyall A, Gilbert D, Wanhill S (2018) Tourism: principles and practice, 6th edn. Pearson, Harlow

14. Gretzel U et al (2020) e-Tourism beyond COVID-19: a call for transformative research. Inf Technol Tour 22(2):187-203. https://doi.org/10.1007/s40558-020-00181-3

15. Guttentag DA (2010) Virtual reality: applications and implications for tourism. Tour Manag 31:637-651. https://doi.org/10.1016/j.tourman.2009.07.003

16. Guttentag DA (2020) Virtual reality and the end of tourism? A substitution acceptance model. In: Xiang Z, Gretzel U, Höpken W (eds) Handbook of e-tourism. Springer, Cham, pp 1-19. https://doi.org/10.1007/978-3-030-05324-6_113-1

17. Hopf J, Scholl M, Neuhofer B, Egger R (2020) Exploring the impact of multisensory on VR travel recommendation: a presence perspective. In: Neidhardt J, Wörndl W (eds) Information and communication technologies in tourism 2020. Springer, Cham, pp 169-180. https://doi.org/10.1007/978-3-030-36737-4

18. Huang YC, Backman KF, Backman SJ, Chang LL (2016) Exploring the implications of virtual reality technology in tourism marketing: an integrated research framework. Int J Tour 18:116-128. https://doi.org/10.1002/jtr.2038

19. Leiper $N$ (1979) The framework of tourism towards a definition of tourism, tourist, and the tourist industry. Ann Tour Res 6:390-407. https://doi.org/10.1016/0160-7383(79)90003-3

20. Lock, S. https://www.statista.com/topics/6224/covid-19-impact-on-the-tourism-industry/

21. McFee A, Mayrhofer T, Baràtovà A, Neuhofer B, Rainoldi M, Egger R (2019) The effects of virtual reality on destination image formation. In: Pesonen J, Neidhardt J (eds) Infor-mation and communication technologies in tourism 2019. Springer, Cham, pp 107-119. https://doi. org/10.1007/978-3-030-05940-8

22. Mechinda P, Serira S, Gulid N (2009) An examination of tourists' attitudinal and behavioral loyalty: comparison between domestic and international tourists. J Vacat Mark 15:129-148. https://doi.org/10.1177/1356766708100820

23. Musil S, Pigel G (1994) Can tourism be replaced by virtual reality technology? In: Schertler W, Schmid B, Tjoa AM, Werthner H (eds) Information and communications technologies in tourism. Springer, Vienna, pp 87-94. https://doi.org/10.1007/978-3-70919343-3_14

24. Prideaux B (2002) The cybertourist. In: Dann GMS (ed) The tourist as a metaphor of the social world. CABI, Wallingford, pp 317-339. https://doi.org/10.1079/9780851996066. 0000

25. Sarkady D, Neuburger L, Egger R (2021) Virtual reality as a travel substitution tool during COVID-19. In: Wörndl W, Koo C, Stienmetz JL (eds) Information and communication technologies in tourism 2021. Springer, Cham, pp 452-463. https://doi.org/10.1007/978-3030-65785-7

26. Smith, C. https://www.news24.com/fin24/companies/travelandleisure/tourism-industrydoubles-down-to-reassure-travellers-20200606-2

27. Tussyadiah IP, Wang D, Jung TH, tom Dieck MC (2018) Virtual reality, presence, and attitude change: empirical evidence from tourism. Tour Manag 66, 140-154. https://doi.org/ 10.1016/j.tourman.2017.12.00

28. United Nations World Tourism Organization. https://www.unwto.org/impact-assessment-ofthe-covid-19-outbreak-on-international-tourism 
29. Williams AP, Hobson JSP (1995) Virtual reality and tourism: fact or fantasy? Tour Manag 16:423-427. https://doi.org/10.1016/0261-5177(95)00050-X

30. Xin S, Tribe J, Chambers D (2013) Conceptual research in tourism. Ann Tour Res 14:66-88. https://doi.org/10.1016/j.annals.2012.12.003

Open Access This chapter is licensed under the terms of the Creative Commons Attribution 4.0 International License (http://creativecommons.org/licenses/by/4.0/), which permits use, sharing, adaptation, distribution and reproduction in any medium or format, as long as you give appropriate credit to the original author(s) and the source, provide a link to the Creative Commons license and indicate if changes were made.

The images or other third party material in this chapter are included in the chapter's Creative Commons license, unless indicated otherwise in a credit line to the material. If material is not included in the chapter's Creative Commons license and your intended use is not permitted by statutory regulation or exceeds the permitted use, you will need to obtain permission directly from the copyright holder. 